\title{
Outcome of RMNCH training of female health workers at regional health and family welfare training centre in northern part of India
}

\author{
Madhvi Kaistha ${ }^{1}$, Tarun Sharma ${ }^{2}$, Vikram Katoch ${ }^{3}$, Urmil Kapoor $^{3}$
}

\author{
${ }^{1}$ Department Of Community Medicine, Gian Sagar Medical College,Banur, Punjab, India \\ ${ }^{2}$ Medical Officer, Kullu, Himachal Pradesh, India \\ ${ }^{3}$ Regional Health and Family Welfare Training Centre Chheb, Kangra, Himachal Pradesh, India
}

Received: 23 October 2015

Revised: 17 December 2015

Accepted: 18 December 2015

\author{
*Correspondence: \\ Dr. Madhvi Kaistha, \\ E-mail: kaisthamadhvi@gmail.com
}

Copyright: ( $)$ the author(s), publisher and licensee Medip Academy. This is an open-access article distributed under the terms of the Creative Commons Attribution Non-Commercial License, which permits unrestricted non-commercial use, distribution, and reproduction in any medium, provided the original work is properly cited.

\begin{abstract}
Background: Reducing maternal and child mortality were among the most important goals of the National Rural Health Mission with aim to increase institutional deliveries. NRHM identified the role of RMNCH councilors for advocacy and communication and social mobilization of disadvantaged people. In Himachal Pradesh Female Health workers were trained as RMNCH councilors at district level. Objectives of the study were to assess the knowledge of female health workers regarding postpartum family planning, reproductive, maternal, newborn and child health before and after administering structured teaching programme, to update knowledge and quality counseling skills on postpartum family planning, reproductive, maternal, newborn and child health and to evaluate the effectiveness of structured teaching programme by comparing the pretest and posttest knowledge scores regarding postpartum family planning, reproductive, maternal, newborn and child health.

Methods: Regional Health and Family Welfare Training Centre, Chheb, Kangra; imparted training to the female health workers of 6 districts. Five days Training was held in three batches of 20 participants each. Didactic lectures were delivered by experienced specialist of public health professionals, gynaecologist and paediatricians. Standardized training material developed by Government of India was used.

Results: A total of 60 participants were enrolled but only 52 participated. The average age of the participants was 35 years \pm 5.7 years. The participants had an average 10 years of working experience. A majority $46 \%$ of these participants were working at Primary Health Centre. Knowledge mean score of various thematic areas of participants increased from mean score of 21.9 to 25.4. It was observed that after training post-test knowledge score showed significant improvement. Paired T test was found to be extremely significant $(\mathrm{p}<0.000)$.

Conclusions: Participants in a short course training focussing on RMNCH had significant improvements in scores on tests of knowledge gained. Widespread implementation of similar training under NRHM may bridge knowledge gaps for various health functionaries but still whether shorter knowledge gains are retained in the longer term remains unknown.
\end{abstract}

Keywords: RMNCH, Councillors, Knowledge

\section{INTRODUCTION}

Reducing maternal and child mortality were among the most important goals of the National Rural Health
Mission with aim to increase institutional deliveries. In 2013, Ministry of Health \& Family Welfare launched an integrated approach for reproductive, maternal, new born, child and adolescent health $(\mathrm{RMNCH}+\mathrm{A})$ in India. ${ }^{1}$ 
RMNCH+A approach addresses the major causes of mortality among women and children as well as the delays in accessing and utilizing health care and services. The $\mathrm{RMNCH}+\mathrm{A}$ approach focus its efforts on the most vulnerable marginalized population and disadvantaged groups. So NRHM identified the role of RMNCH councillors for advocacy and communication and social mobilization of disadvantaged people. ${ }^{1}$

With increase in institutional deliveries facilitated by JSY scheme, the doctors and nurses at the public health facilities remain busy with conducting deliveries and providing clinical services. With increase in institutional deliveries they are unable to devote much time on counselling. It is a well-recognized fact that effective counselling of women and couples is critical to increase the acceptability and adoption of evidence based best practices by women and couples that improve maternal, new-born and child health.

It has been observed that good practices related to mother, child and family planning are adopted and practiced only when these clients make their own decision based on correct knowledge. Effective counselling is the means which empowers these clients to seek information and take decision. To complement the health services provided by clinical staff, reproductive, maternal, new born and child health (RMNCH) counsellors are identified as catalytic agents, who can provide quality counselling for reproductive, maternal, new-born, child health ( $\mathrm{RMNCH}$ ) services to women, couples and family members attending the health facility.

In Himachal Pradesh female Health workers were trained as RMNCH councillors at district level. Keeping this in view, a 5 day knowledge and skill enhancing training was designed and conducted at the Regional Health and Family Welfare Training Centre Chebb, Kangra, Himachal Pradesh.

\section{Aim}

To enhance the competency of facility based RMNCH counsellors so that they can effectively create awareness and counsel women, couples, and family members coming to the public health facilities.

\section{Objectives of the training}

1. To assess the knowledge of female health workers regarding postpartum family planning, reproductive, maternal, new-born and child health before and after administering structured teaching programme.

2. Update knowledge and quality counselling skills on postpartum family planning; reproductive, maternal, newborn and child health.

3. To evaluate the effectiveness of structured teaching programme by comparing the pre-test and post-test knowledge scores regarding postpartum family planning, reproductive, maternal, new-born and child health.

\section{METHODS}

Regional Health And Family Welfare Training Centre, Chheb, Kangra is a premiere institute in Himachal Pradesh which routinely imparts training to all the health care functionaries working at different levels of health care institutions of 6 districts.. Training was held in three batches. The trainers team consisted of One RMNCHA Facilitators (public health specialist), faculty of medical college including gynaecologist, paediatrician and Social worker (state TOT for RMNCH Councillor's. The trainees were health workers and were directed by their Chief Medical Officers to attend this training. The recruitment of participants to a particular batch was not controlled by investigators. Each batch consisted of 20 participants, who were nominated by their respective Block Medical Officers. The key focus of the training was to build the competency of participants through repeated simulated practice of counselling in the classroom and hospital setting, using simple counselling skills checklists and job-aids. The case studies were done at medical college because of its easy access.

The conventional four day training package was delivered as per national guidelines and the fifth day was added for training in various newly introduced various health programs related to maternal and child health including an important gender sensitization lecture. Standardized training material developed by Government of India was used.

Didactic lectures were delivered by experienced specialist of public health professionals, gynaecologist and paediatrician in the forenoon while in afternoon visit to field were conducted for translating learning into practice sessions. Various determinants of maternal and child health were discussed and counselling method were demonstrated in the clinical and community settings.

A variety of training activities like interactive presentation, group activities, case studies and role-plays were included which established an energetic and positive learning environment. The assessment of the participants was done for knowledge and its related counselling skills at the beginning and end of each thematic area. The purpose of this assessment is to assess the gain in knowledge and skills through training. A multiple choice questionnaire was administered before and after the training to asses' participant knowledge of relevant thematic areas i.e. family planning, maternal and newborn health, child health and counselling skills. Scoring criteria: For each correct answer, the participant got one mark, for each incorrect answer or question not attempted the participant got 0 marks. For evaluating score percentage, following formula: X (Marks obtained) $/ 10 \times$ $100=\ldots \ldots \ldots \ldots \%$ was used.

The accepted level in post-test was $80 \%$. Those who received below $80 \%$ were called for one-to-one 
discussion of his/her paper and if needed, again called for training.

\section{RESULTS}

75 A total of 60 participants were enrolled but only 52 participated. The average age of the participants was 35 years \pm 5.7 years. The participants had an average 10 years of working experience. A majority $46 \%$ of these participants were working at primary health centre.

Table 1 shows knowledge mean score of various thematic areas of participants increased from mean score of 21.9 to 25.4. It was observed that after training posttest knowledge score showed significant improvement.

Table 1: Knowledge mean score of various thematic areas.

\begin{tabular}{|c|c|c|c|c|}
\hline $\begin{array}{l}\text { Mean } \\
\text { score }\end{array}$ & Pretest & Post test & $\begin{array}{l}\% \\
\text { increase }\end{array}$ & $\begin{array}{l}\mathbf{P} \\
\text { value* }\end{array}$ \\
\hline $\begin{array}{l}\text { Family } \\
\text { planning }\end{array}$ & $\begin{array}{l}6.8 \\
(68 \%)\end{array}$ & $7.8(78 \%)$ & 10 & \multirow{4}{*}{$<0.000$} \\
\hline $\begin{array}{l}\text { Maternal } \\
\text { and } \\
\text { newborn }\end{array}$ & $\begin{array}{l}8.1 \\
(81 \%)\end{array}$ & $9.6(96 \%)$ & 15 & \\
\hline $\begin{array}{l}\text { Child } \\
\text { health }\end{array}$ & $\begin{array}{l}6.9 \\
(69 \%)\end{array}$ & $8.0(80 \%)$ & 11 & \\
\hline Total & $\begin{array}{l}21.9 \\
(73 \%)\end{array}$ & $\begin{array}{l}25.4(84 . \\
7 \%)\end{array}$ & 11.7 & \\
\hline
\end{tabular}

*p value based on paired $\mathrm{T}$ test for means.

Paired $\mathrm{T}$ test was found to be extremely significant $(\mathrm{p}<0.000)$.

Figure no.1 shows pre and post test scores of the participants.



Figure 1: Test scores of various thematic areas of the participants.

It was observed that $50 \%$ of the participants knowledge score improved to more than $80 \%$ after training (Table 2).
Table 2: Knowledge score in terms of percentage.

\begin{tabular}{|lll|}
\hline Knowledge Score & $\begin{array}{l}\text { Pre Test } \\
\mathbf{N}(\%)\end{array}$ & $\begin{array}{l}\text { Post Test } \\
\mathbf{N}(\%)\end{array}$ \\
\hline $100 \%-90 \%$ & $8(15.3)$ & $13(25)$ \\
\hline $89 \%-80 \%$ & $6(12.1)$ & $13(25)$ \\
\hline $79 \%-70 \%$ & $7(13.4)$ & $15(28.8)$ \\
\hline $69-60 \%$ & $12(23.1)$ & $7(13.5)$ \\
\hline$<60 \%$ & $19(36.5)$ & $4(7.7)$ \\
\hline
\end{tabular}

\section{DISCUSSION}

Appropriate knowledge and interpersonal communication expertise, in addition to basic clinical skills, supplies and supervision, is a key to the work of community health workers. $^{2}$

Our study evaluating the knowledge transfer and quality counseling skill among participants of a training course directed at health workers suggests that a short, intensive exposure to various reproductive, maternal, newborn, and child thematic areas resulted in a significant improvement in scores on tests of knowledge acquired. These workers can be of great help in acting as RMNCH councilors as WHO has suggested that Community health workers have been used in many settings for plugging the gaps in service delivery, when skilled personnel cannot be deployed for any reason. ${ }^{3}$

The magnitude of increase in our study test scores, greater than $10 \%$, in all the thematic areas was large and statistically significant, similar to other studies elsewhere. ${ }^{4}$

Several other studies have found improvements following a course conducted by Sprague $S$ et al a 2.5-day evidence-based medicine for surgeons showed improvement up to 10 points while a course conducted by $\mathrm{K}$ Dinesh et al, in AYUSH practitioner, knowledge of the participants has shown much higher improvement up to 30 points, and an 8-day Integrated Management of Neonatal and Childhood Illness (IMNCI) showed improvement upto 40 points. $^{5-7}$

Various communication aids were used in the present training which helped in the significant improvement of knowledge. Demonstration and skill acquiring sessions was also observed to be very effective in acquiring knowledge. 8 Various studies have shown that Skills based training accommodates the different learning styles of participants; helps diminish the gap between theory and practice and may allow for a better integration of theoretical concepts. ${ }^{10}$

In our study standardized health education material was used to focus attention, to provide new knowledge, to facilitate interpersonal and group discussions and reinforce or clarify prior knowledge and behavior. Another study suggest that Community health workers 
have made a measureable impact on health indicators by bridging the gap between community and the health care delivery system, enhancing health service utilization and creating awareness about health practices among people through health education. ${ }^{11}$

Our study had several strengths, including the use of a pre- and post-training test study design; use of validated questionnaire given in the facilitators guide. ${ }^{1}$ The 3 questionnaires used in the testing covered all of the key aspects of the course content. The study was also strengthened by timing of the administration of the questionnaires, limiting the risk of contamination.

\section{Limitations}

Although $100 \%$ participants completed the pre and post post course test, there were observed extreme knowledge test scores; whereas some participants excelled (obtained a score of 100-90\%), others did not (obtained a score less than 50\%). It remains plausible that participants who initially felt uncomfortable with the training neglected to complete the pre course test, as the participants were well aware of the various thematic areas. Another limitation, Given that the tests did not impact the success of a participant's completion and certification of attendance, some may have been less motivated to put effort into the tests, which may have affected their scores. Along with partnered with a small sample size, accounts for the wide range of score we reported. Finally, we cannot generalize the short-term improvements that we observed to sustained longer-term knowledge about various thematic areas.

\section{CONCLUSION}

Participants in a short course training focussing on RMNCH had significant improvements in scores on tests of knowledge gained. Widespread implementation of similar training under NRHM may bridge knowledge gaps for various health functionaries but still whether shorter knowledge gains are retained in the longer term remains.

\section{Recommendations}

Health workers are trained regularly in different programs but as counseling plays a very important role in behavior approach of population, so further field based evaluation is needed to assess the practical impact of training and outcome is to be studied. Creating skill labs with linkages for post training mentoring is one intervention that can be used to accomplish this.

\section{Funding: No funding sources} Conflict of interest: None declared

Ethical approval: The study was approved by the Institutional Ethics Committee

\section{REFERENCES}

1. Government of India, Ministry of Health and Family Welfare, Family Planning Division. Facilitators' Guide for Training of Reproductive, Maternal, Neonatal, and Child Health (RMNCH); 2013.

2. World Health Organization. Community Health Workers: What Do We Know About Them? Evidence and Information for Policy, Department of Human Resources for Health, Geneva; 2007.

3. Standing H, Chowdhury HM. Producing effective knowledge agents in a pluralistic environment: what future for community health workers? Soc Sci Med. 2008;66(10):2096-107.

4. Sibley JC, Sackett DL, Neufeld V, Gerrard B, Rudnick KV, Fraser W. A randomized trial of continuing medical education. The New England journal of medicine. 1982;306(9):511-5.

5. Kumar D, Raina SK, Bhardwaj AK, Chander V. Capacity building of AYUSH practitioners to study the feasibility of their involvement in noncommunicable disease prevention and control. Anc Sci Life. 2012;32(2):116-9.

6. Sprague S, Pozdinakova P, Kaempffer E, Saccone M, Schemitsch EH, Bhandari M. Principles and practice of clinical research course for surgeons: An evaluation of knowledge transfer and perceptions. Can J Surg. 2012;55:46-52.

7. Kumar D, Aggarwal AK, Kumar R. Interrupted 5day training on Integrated Management of Neonatal and Childhood Illness (IMNCI): Effect on the knowledge and skills of primary health. Health Policy Plan. 2009;24:94-100.

8. Sangestani G, Khatiban M. Comparison of problembased learning and lecture-based learning in midwifery. Nurse education today. 2013;33(8):7915.

9. Dehkordi AH, Heydarnejad MS. The impact of problem-based learning and lecturing on the behavior and attitudes of Iranian nursing students. A randomised controlled trial. Dan Med Bull. 2008;55:224-6.

10. Eldarir SA, Nagwa A, Hamid A. Objective Structured Clinical Evaluation (OSCE) versus Traditional Clinical Students Achievement at Maternity Nursing: A comparative approach. IOSR Journal of Dental and Medical Sciences. 2013;4:638.

11. Haq Z, Hafeez A. Knowledge and communication needs assessment of community health workers in developing countries: a qualitative study. Hum Res Health. 2009;7:59.

Cite this article as: Kaistha M, Katoch V, Sharma T, Kapoor U. Outcome of RMNCH training of female health workers at regional health and family welfare training centre in northern part of India. Int J Community Med Public Health 2016;3:204-7. 